\title{
Predictive and prognostic role of activated mammalian target of rapamycin in cervical cancer treated with cisplatin-based neoadjuvant chemotherapy
}

\author{
LERI S. FARIED ${ }^{1}$, AHMAD FARIED ${ }^{2}$, TATSUYA KANUMA ${ }^{1}$, TAKAAKI SANO ${ }^{3}$, TOMOKO NAKAZATO $^{1}$, \\ TOMOHIRO TAMURA $^{1}$, HIROYUKI KUWANO ${ }^{2}$ and TAKASHI MINEGISHI ${ }^{1}$ \\ ${ }^{1}$ Department of Gynecology and Reproductive Medicine; ${ }^{2}$ Department of General Surgical Science (Surgery I); \\ ${ }^{3}$ Department of Tumor Pathology, Graduate School of Medicine, Gunma University, \\ 3-39-22 Showa-machi, Maebashi, Gunma 371-8511, Japan
}

Received February 2, 2006; Accepted April 6, 2006

\begin{abstract}
The present study was designed to clarify the expression and prognostic significance of activated Akt and mTOR in cervical cancer and their correlation with response to neoadjuvant chemotherapy (NAC). Immunohistochemical analysis for p-Akt and p-mTOR expression was performed on paraffin-embedded biopsy specimens from 25 patients with advanced cervical cancer (stage Ib2-IIb). We correlated this finding with various clinicopathological variables and prognosis by uni- and multivariate analyses. All patients received cisplatin-based NAC, and primary tumor response was evaluated by RECIST criteria and then classified as a positive or negative response. Activation of Akt was detected in the cytoplasm and nucleus of the cancer cells in 12 patients $(48 \%)$, whereas p-mTOR was detected in the cytoplasm and membrane of the cancer cells in 13 patients (52\%). Post NAC evaluation of the primary tumor revealed $68 \%$ (17/25) responsive tumors. The expression of $\mathrm{p}-\mathrm{mTOR}$ and distant metastasis significantly correlated with the response to NAC ( $p=0.0101$ and $\mathrm{p}=0.0107$ ); however, there was no significant correlation between p-Akt and p-mTOR expression and any of the clinicopathological characteristics of the patients. In the univariate analysis, activated Akt and mTOR were found to be significant prognostic indicators $(\mathrm{p}<0.05)$. In multivariate analysis, $\mathrm{p}-\mathrm{mTOR}$ expression retained its significance as an independent poor prognostic marker $(\mathrm{p}=0.0178)$. In summary, our present study showed that cervical cancer expressed Akt and mTOR activation. Moreover, the expression of phosphorylated mTOR may have a role as a marker to predict response to
\end{abstract}

Correspondence to: Dr L.S. Faried, Department of Gynecology and Reproductive Medicine, Graduate School of Medicine, Gunma University, 3-39-22 Showa-machi, Maebashi, Gunma 371-8511, Japan

E-mail: leri@med.gunma-u.ac.jp

Key words: cervical cancer, immunohistochemistry, p-Akt, activated mammalian target of rapamycin, prognosis chemotherapy and survival of cervical cancer patients who are treated with cisplatin-based neoadjuvant chemotherapy. Our results suggest that the mTOR cascade may be a promising target for therapeutic intervention in cervical cancer.

\section{Introduction}

Carcinoma of the cervix is the second most common neoplasm in women worldwide. Its incidence is the highest in developing countries, where organized screening programs with the Pap test have not been well implemented $(1,2)$. The best possible treatment of locally advanced cervical cancer is a combination of radiation and cisplatin-based chemotherapy. However, the five-year overall survival is still only $52 \%$ (3), and the FIGO data from 1993 to 1995 also indicate that the prognosis of advanced cervical cancer remains poor (4). From this data, it is suggested that conventional treatment methods have reached a plateau and therefore, finding a good prognostic factor and predictor response to chemotherapy might be useful for overcoming this problem.

Akt or protein kinase B (PKB) is the cellular homologue product of the $\mathrm{V}$-akt oncogene and is activated downstream from phosphatidylinositol 3-kinase (PI3K) by a variety of growth factors (5). Activation of Akt pathway has been proposed to be involved in oncogenesis and resistance to cancer therapy. The main consequences of Akt activation can be catalogued into three categories: survival, proliferation (increased cell number), and growth (increased cell size). One protein that is emerging as a central regulator of cell growth is mTOR, also known as FRAP1 (FKBP 12-rapamycinassociated protein 1), a serine/threonine kinase that serves as a molecular sensor in regulating protein synthesis on the basis of the availability of nutrients $(6,7)$. However, the PI3K-Akt pathway is unlikely to be the only stimulus that leads to mTOR activation in cancer cells. For example, mTOR can also function as an ATP sensor (8). Recently, Wlodarski and colleagues reported that the activation of mTOR in transformed B lymphocytes is nutrient-dependent and independent of Akt, mitogen-activated protein kinase kinase, insulin growth factor-I, and serum (9). Therefore, the exact mechanism of the activation of mTOR signaling is still poorly understood. 
This study was designed to observe the expression and prognostic significance of p-Akt and p-mTOR and their predictive value in the response to chemotherapy. Although several studies have reported that the expression of activated Akt and mTOR is implicated in human cancers, until the present time, to our knowledge, no reports on cervical cancer have been published.

\section{Patients and methods}

Patients. Archival biopsy specimens from 25 patients with advanced cervical cancer (stage Ib2-IIb) at the Gunma University Hospital, Japan, between 1995 and 2002 were analyzed and the study was conducted according to the ethical guidelines of our university. The ages of the patients ranged from 25 to 57 years, with a mean age of 45 years. Squamous cell carcinoma was the most frequent cancer subtype with 19 cases and there were 6 cases of adenosquamous carcinoma. Stages were determined according to the clinical criteria established by the International Federation of Gynecology and Obstetrics (FIGO) in 1994 (10). All patients had cisplatin-based NAC (POMP: cisplatin, vincristine, mitomycinc). After 2 to 3 cycles of chemotherapy, it was decided whether radical hysterectomy was possible. Response evaluation to NAC was carried out every 3 months during follow-up based on RECIST (response evaluation criteria in solid tumors) criteria (11). The response was assessed with MRI. Patients were then divided into two groups, positive response (complete and partial response) and negative response (stable disease and progressive disease). Formalin-fixed and paraffin-embedded biopsies samples of the patients were obtained before the start of NAC and retrieved from the department of pathology after review of histological diagnosis on hematoxylin and eosin (H\&E)-stained sections.

Immunohistochemistry. Immunohistochemical staining of the section for p-Akt and p-mTOR were performed using the streptoavidin-biotin method. Sections (4- $\mu \mathrm{m}$ thick) were deparaffinized with xylene, rehydrated, and incubated with fresh $0.3 \%$ hydrogen peroxide in methanol for $30 \mathrm{~min}$ at room temperature. After rehydration through a graded ethanol series, the specimens were washed in phosphate-buffered saline (PBS). After a blocking treatment, the specimens were then incubated with the primary anti-p-Akt and anti-p-mTOR antibody (Cell Signaling Technology, Beverly, MA) at a dilution of 1:200, respectively in PBS containing 1\% bovine serum albumin (BSA) at $4^{\circ} \mathrm{C}$ overnight. They were then washed with PBS and incubated in secondary antibody for $30 \mathrm{~min}$ at room temperature. Immunohistochemistry was performed using a Histofine SAB-PO (M) kit (Nichirei, Tokyo, Japan). The chromogen was a $3.3-0.02 \%$ solution containing $0.005 \% \mathrm{H}_{2} \mathrm{O}_{2}$ in a $50 \mathrm{mM}$ ammonium acetate-citric acid buffer, $\mathrm{pH}$ 6.0. The specimens were lightly counterstained with haematoxylin. Negative controls were prepared by omitting each primary antibody; no detectable staining was evident.

Evaluation. The staining evaluation was performed by two independent observers who did not have any knowledge of the clinical outcome. For p-Akt and p-mTOR, total staining was scored as the product of the staining intensity (on a scale of 0-3) x percentage of cells stained, resulting in a scale of $0-300$. Staining intensity was scored as follows: 0 , no appreciable staining in tumor cells; 1 , barely detectable staining in cytoplasm, nucleus, or membrane, as compared with stromal elements; 2 , readily appreciable brown staining distinctly marking tumor cell cytoplasm, nucleus, or membrane; and 3, dark brown staining in tumor cells completely obscuring cytoplasm, nucleus, or membrane (12). The data were then classified as null (0), weak (1-100), moderate (101-200), or strong (201-300) p-Akt or p-mTOR staining. This scoring system has been reported previously (13).

For purposes of statistical analysis, all cases staining at a null or weak level were grouped as negative and all cases staining at a moderate or strong level were grouped as positive.

Statistics. Statistical analysis was performed using the Stat View software program (version 5, SAS Institute, NC, USA). The unpaired two-group t-test was used for age, p-Akt expression and p-mTOR expression. A Chi-squared test was used for histological type, FIGO stage, lymphatic invasion, lymph node metastasis, distant metastasis, and venous invasion. Survival curves of the patients were calculated using the Kaplan-Meier method and analysis was performed using the log-rank test. The Cox proportional hazards model for the risk ratio was used to assess the simultaneous contribution of levels of p-Akt and p-mTOR to the survival rate. Significant differences were noted when $\mathrm{P}<0.05$.

\section{Results}

Expression of $p$-Akt and p-mTOR in cervical cancer. To elucidate the expression status and localization of $\mathrm{p}$-Akt and p-mTOR in cervical cancer patients, we performed immunohistochemical analysis, using p-Akt (Ser473) and p-mTOR (Ser2448) antibody on 25 biopsy samples from patients with advanced cervical cancer; paired normal cervical tissues were used as controls. Fig. 1 shows representative immunohistochemical staining of cervical cancer. Fig. 1A and E shows a negative control, in which the primary anti p-Akt and p-mTOR was omitted. Negative controls were uniformly negative for immunostaining. Weak-to-strong nuclear and/or cytoplasmic staining of p-Akt was observed in primary tumor cells, and faint expression was seen in the surrounding stromal area (Fig. 1B-D). Positive staining of activated mTOR was detected in the cytoplasm and membrane (Fig. 1F-H). Positive staining for p-Akt and p-mTOR was seen in 12 of $25(48 \%)$ and 13 of $25(52 \%)$ biopsy specimens, respectively.

Correlation between clinicopathological outcome and the expression of $p$-Akt and p-mTOR. The correlations between the clinicopathological characteristics of patients with cervical cancer and the expression of p-Akt and p-mTOR in their tumors are summarized in Table I. Although cancer with activated Akt and mTOR tended to be associated with poorer lymphatic invasion status $(\mathrm{p}=0.13$ and $\mathrm{p}=0.06)$, there was no significant correlation between positive $\mathrm{p}$-Akt and p-mTOR with any cervical cancer pathological (histological type, lymphatic invasion, lymph node metastasis, venous invasion) or clinical (patient age and staging) outcome. The relationship between clinicopathological features and response 
Table I. Correlation of p-Akt and p-mTOR expression with clinicopathological outcome in advanced cervical cancer.

\begin{tabular}{|c|c|c|c|c|c|c|c|}
\hline Parameter & $\begin{array}{l}\text { Total } \\
n=25\end{array}$ & $\begin{array}{c}\mathrm{p}-\text { Akt }(-) \\
\mathrm{n}=13\end{array}$ & $\begin{array}{c}\mathrm{p}-\mathrm{Akt}(+) \\
\mathrm{n}=12\end{array}$ & $\mathrm{p}$ value & $\begin{array}{c}\text { p-mTOR (-) } \\
n=12\end{array}$ & $\begin{array}{c}\mathrm{p}-\mathrm{mTOR}(+) \\
\mathrm{n}=13\end{array}$ & $\mathrm{p}$ value \\
\hline Age (mean \pm SD years) & $45.0 \pm 9.0$ & $46.2 \pm 6.3$ & $45.4 \pm 10.5$ & 0.83 & $47.2 \pm 6.1$ & $44.5 \pm 10.1$ & 0.45 \\
\hline \multicolumn{8}{|l|}{ Histological type } \\
\hline Squamous & 19 & 9 & 10 & 0.4 & 8 & 11 & 0.29 \\
\hline Adenosquamous & 6 & 4 & 2 & & 4 & 2 & \\
\hline \multicolumn{8}{|l|}{ FIGO stage } \\
\hline $\mathrm{Ib} 2$ & 3 & 2 & 1 & 0.7 & 2 & 1 & 0.7 \\
\hline IIa & 3 & 2 & 1 & & 1 & 2 & \\
\hline IIb & 19 & 9 & 10 & & 9 & 10 & \\
\hline \multicolumn{8}{|l|}{ Lympathic invasion } \\
\hline Absent & 13 & 6 & 7 & 0.13 & 5 & 10 & 0.06 \\
\hline Present & 12 & 9 & 3 & & 7 & 3 & \\
\hline \multicolumn{8}{|l|}{ Lymph node metastasis } \\
\hline Absent & 17 & 10 & 7 & 0.31 & 9 & 8 & 0.47 \\
\hline Present & 8 & 3 & 5 & & 3 & 5 & \\
\hline \multicolumn{8}{|l|}{ Distant metastasis } \\
\hline Absent & 20 & 11 & 9 & 0.54 & 11 & 9 & 0.14 \\
\hline Present & 5 & 2 & 3 & & 1 & 4 & \\
\hline \multicolumn{8}{|l|}{ Venous invasion } \\
\hline Absent & 19 & 10 & 9 & 0.91 & 8 & 11 & 0.29 \\
\hline Present & 6 & 3 & 3 & & 4 & 2 & \\
\hline
\end{tabular}

SD, standard deviation; FIGO, Federation Internationale de Gynecologic et d' Obstetrique.

to NAC is summarized in Table II. The positive response of the primary tumor was $68 \%(17 / 25)$. We found that $91.67 \%$ $(11 / 12)$ of the $\mathrm{p}-\mathrm{mTOR}$-negative group had a positive response, in comparison to $46.15 \%(6 / 13)$ of the p-mTORpositive group. A statistical significance was observed between distant metastasis and p-mTOR expression and response to NAC $(p=0.010$ and $p=0.011)$.

Correlation between expression of $p$-Akt and $p-m T O R$ and survival. The expression of $\mathrm{p}$-Akt and $\mathrm{p}$-mTOR has been reported to be a predictor of poor prognosis in some cancers $(13,14)$. The survival rates of patients with positive and negative expression of $\mathrm{p}$-Akt and p-mTOR were then further analyzed. The survival rate for cervical cancer patients with negative $\mathrm{p}$-Akt was significantly higher than that for patients with positive $\mathrm{p}$-Akt expression ( $\mathrm{p}=0.005$; Fig. 2 ). The fiveyear survival rates for patients with negative and positive p-Akt were $52 \%$ and $48 \%$, respectively. In addition, p-mTOR was also significantly correlated with the five-year survival rates ( $\mathrm{p}=0.019$; Fig. 3 ). To clarify whether their expression is a significant prognostic factor, uni- and multivariate survival analyses were performed, and the analyses showed that p-mTOR expression was independently associated with the prognosis of cervical cancer patients (Table III).

\section{Discussion}

The role of the activation of Akt and mTOR has been well characterized in many human cancers. Akt has a critical role in several signaling pathways, including survival, apoptosis, and proliferation. The well-known downstream target of Akt in survival signaling is mTOR (6).

This study showed that Akt and mTOR are expressed and activated in cervical cancer. Of the 25 cases of cervical cancer studied, positive activated Akt and mTOR expression was observed in $48 \%$ and $52 \%$, respectively. Although PTEN (phosphatase and tensin homologue deleted on chromosome 10) is well characterized to negatively regulate $\mathrm{PKB} / \mathrm{Akt}$ activation, [primarily through phosphatidylinositol-3,4,5-triphosphate (PIP3) dephosphorylation (15)], none of the cervical cancer cases showed mutation of the PTEN protein $(16,17)$. As one possible explanation for our results, a previous study reported that the PIK3CA gene, which encodes the $\mathrm{p} 110 \alpha$ catalytic subunit of PI3K, is frequently amplified in cervical cancer (18). In addition, a number of studies have discovered PKB/Akt gene amplifications in human cancers. No modified or mutated Akt genes have been found in mammals. Its activation may also be due to the activation of up-stream regulators of 
Table II. Correlation of clinicopathological outcome with response to chemotherapy.

\begin{tabular}{|c|c|c|c|c|}
\hline Parameter & $\begin{array}{l}\text { Total } \\
n=25\end{array}$ & $\begin{array}{l}\text { Response }(+) \\
\mathrm{n}=17\end{array}$ & $\begin{array}{c}\text { Response } \\
\mathrm{n}=8\end{array}$ & $\mathrm{p}$ value \\
\hline Age (mean \pm SD years) & $45.0 \pm 9.0$ & $46.710 \pm 7.573$ & $43.875 \pm 10.176$ & 0.443 \\
\hline \multicolumn{5}{|l|}{ Histological type } \\
\hline Squamous & 19 & 13 & 6 & 0.936 \\
\hline Adenosquamous & 6 & 4 & 2 & \\
\hline \multicolumn{5}{|l|}{ FIGO stage } \\
\hline $\mathrm{Ib} 2$ & 3 & 3 & 0 & 0.445 \\
\hline IIa & 3 & 2 & 1 & \\
\hline $\mathrm{IIb}$ & 19 & 12 & 7 & \\
\hline \multicolumn{5}{|l|}{ Lympathic invasion } \\
\hline Absent & 13 & 9 & 6 & 0.285 \\
\hline Present & 12 & 8 & 2 & \\
\hline \multicolumn{5}{|l|}{ Lymph node metastasis } \\
\hline Absent & 17 & 12 & 5 & 0.686 \\
\hline Present & 8 & 5 & 3 & \\
\hline \multicolumn{5}{|l|}{ Distant metastasis } \\
\hline Absent & 20 & 16 & 4 & $0.010^{\mathrm{a}}$ \\
\hline Present & 5 & 1 & 4 & \\
\hline \multicolumn{5}{|l|}{ Venous invasion } \\
\hline Absent & 19 & 13 & 6 & 0.936 \\
\hline Present & 6 & 4 & 2 & \\
\hline \multicolumn{5}{|l|}{ p-Akt } \\
\hline Negative & 13 & 11 & 2 & 0.059 \\
\hline Positive & 12 & 6 & 6 & \\
\hline \multicolumn{5}{|l|}{ p-mTOR } \\
\hline Negative & 12 & 11 & 1 & $0.011^{\mathrm{a}}$ \\
\hline Positive & 13 & 6 & 7 & \\
\hline
\end{tabular}

SD, standard deviation; FIGO, Federation Internationale de Gynecologie et d'Obstetrique; aSignificant.

Table III. Prognostic factors of patients with invasive cervical cancer in Cox proportional hazards model.

\begin{tabular}{|c|c|c|c|c|c|c|}
\hline \multirow[b]{2}{*}{ Risk factor } & \multicolumn{3}{|c|}{ Univariate } & \multicolumn{3}{|c|}{ Multivariate } \\
\hline & Hazard ratio & $95 \% \mathrm{CI}$ & $\mathrm{p}$ value & Hazard ratio & $95 \% \mathrm{CI}$ & $\mathrm{p}$ value \\
\hline Lymphatic invasion & 1.436 & $0.649-3.448$ & 0.345 & 1.133 & $0.409-3.136$ & 0.81 \\
\hline Venous invasion & 1.254 & $0.463-3.397$ & 0.657 & 1.684 & $0.835-3.396$ & 0.146 \\
\hline Lymph node metastasis & 1.078 & $0.445-2.612$ & 0.868 & 0.88 & $0.492-1.671$ & 0.665 \\
\hline Distant metastasis & 0.269 & $0.087-0.828$ & $0.022^{\mathrm{a}}$ & 0.412 & $0.117-1.449$ & 0.167 \\
\hline p-Akt expression in IHC & 0.303 & $0.116-0.787$ & $0.047^{\mathrm{a}}$ & 1.351 & $0.857-2.130$ & 0.195 \\
\hline p-mTOR expression in IHC & 0.042 & $0.182-0.990$ & $0.014^{\mathrm{a}}$ & 2.00 & $41.128-3.562$ & $0.018^{\mathrm{a}}$ \\
\hline
\end{tabular}

IHC, immunohistochemistry; CI, confidence interval; ${ }^{\text {a Significant. }}$

PI3K, such as tyrosine-kinase, G-protein-coupled receptors, and integrins (19).

Similarly to previous reports (20-22), our present study showed that activated Akt was detected in the cytoplasm and nucleus of cervical cancer cells, whereas mTOR was observed in the cytoplasm and membrane. Other studies reported that p-Akt staining in breast and prostate cancer was mainly localized in the cell membrane $(14,23)$ while, in epithelial ovarian carcinoma, a predominant nuclear localization was observed (24). It is well characterized that Akt is activated 

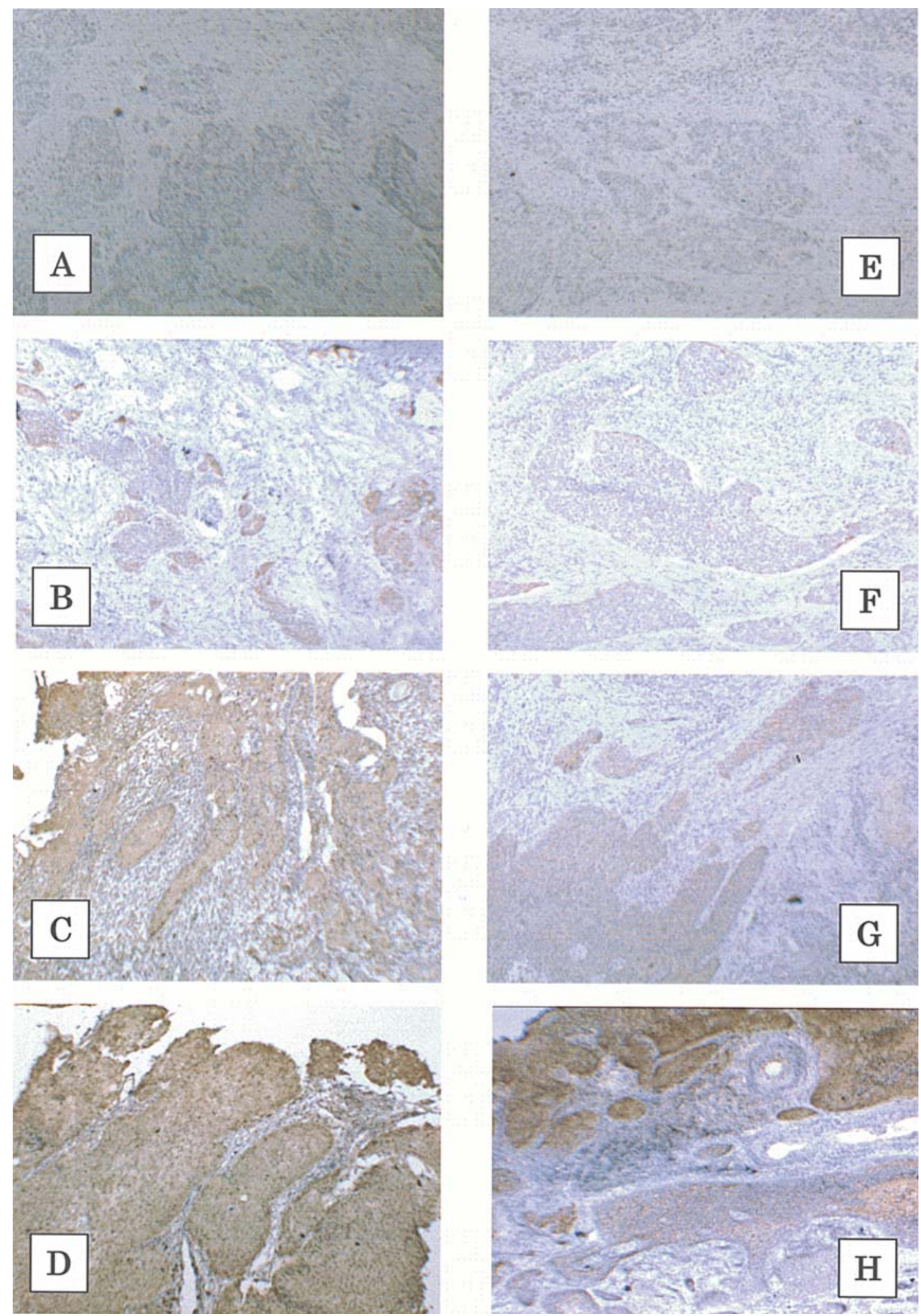

Figure 1. Representative immunostaining of human cervical cancer for phosphorylated Akt (A-D) and mTOR (E-H); A and E, negative control, no immunoreactive p-Akt and p-mTOR was detected; B-D, weak to strong expression of p-Akt was detected in cytoplasm and nucleus; F-H, weak to strong expression of p-mTOR was detected in cytoplasm and membrane (original magnification of x100).

in cells exposed to diverse stimuli, such as hormones, growth factors, and extracellular matrix components. The activation mechanism remains to be fully characterized, but it appears to occur downstream of PI3K. PI3K generates PIP3, a lipid second messenger essential for the translocation of Akt to the plasma membrane, where it is phosphorylated and activated by phosphoinositide-dependent kinase-1 (PDK1) and, possibly, other kinases (19). Akt directly phosphorylates and modifies its downstream effectors, such as mTOR, forkhead transcription factors FKHRL1, FHH1, and AFX, IKK $\alpha$, 


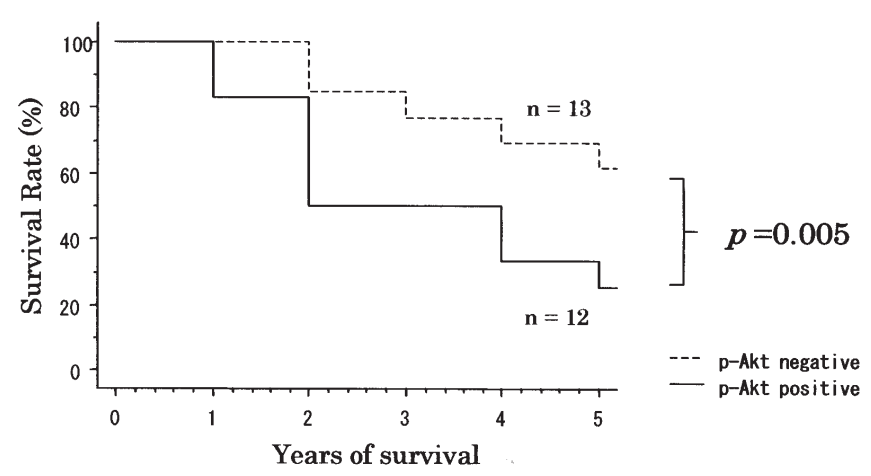

Figure 2. Kaplan-Meier estimates of overall survival for patients with cervical cancer grouped according to p-Akt expression. Patients with negative $\mathrm{p}$-Akt had significantly more favorable prognosis than those with positive p-Akt expression. P-value was determined using the log-rank test.

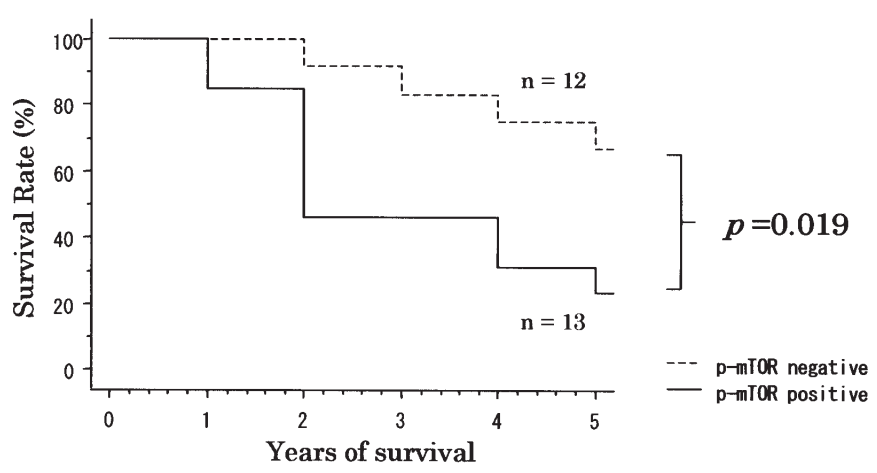

Figure 3. Kaplan-Meier estimates of overall survival for patients with cervical cancer grouped according to p-mTOR expression. Patients with negative p-mTOR had significantly more favorable prognosis than those with positive p-mTOR expression. P-value was determined using the logrank test.

caspase-9, telomerase, glycogen synthase kinase 3 (GSK3), BAD, and others $(19,25-27)$. The majority of these targets are located in the cytosol, but some appear to be primarily phosphorylated by Akt in the nucleus (19); therefore, it is possible to detect the different localization of activated Akt according to its downstream target.

Although p-Akt and p-mTOR expression tended to be related to lymphatic invasion, there was no significant correlation between $\mathrm{p}$-Akt and p-mTOR expression with the clinicopathological characteristics of the patients. We also investigated whether the activation of Akt and mTOR correlates with the response to NAC. The majority of patients in this study were treated with cisplatin, vincristine, and mitomycin-c (POMP) before surgery, and the response to chemotherapy was evaluated based on RECIST criteria (11). A significant inverse correlation between expression of phosphorylated mTOR and chemotherapy response was found. Activated mTOR in correlation with chemosensitivity has been investigated in vitro and in vivo $(28,29)$. Recently, Beuvink and colleagues showed that the inhibition of mTOR activation sensitized tumor cells to DNA-damaged induced apoptosis through inhibition of p21 translation (30). These results indicate that evaluation of mTOR expression in cervical cancer would be useful in predicting the response to chemotherapy. Patients will benefit the most when there is accurate information available about the effect of treatment before treatment is started.

In the present study, the expression of activated Akt and mTOR in cervical cancer also correlated with poor prognosis, and multivariate analysis revealed that mTOR represents an independent prognostic factor. Similar results have been reported for cancers of other organs, such as prostate, pancreas, and thyroid, and melanoma (13,22,31-33). Yamamoto and colleagues (31) indicated that p-Akt expression is an independent prognostic indicator for pancreatic ductal adenocarcinoma. In addition, Zhou and colleagues (22) reported that activation of the Akt/mTOR/4E-BP1 pathway predicts tumor progression in breast cancer. The best-characterized function of mTOR in mammalian cells is the regulation of translation. S6K and 4EBP1 are key regulators of protein translation (7). S6K is the major ribosomal protein S6 kinase in mammalian cells (34). Its activation results in an enhancement of the overall translation capacity of the cells (35). 4EBP1, another well-characterized mTOR target, acts as a translational repressor by binding and inhibiting the eukaryotic translation initiation factor 4E (eIF4E). Phosphorylation of 4EBP1 by mTOR results in a dissociation of 4EBP1 from eIF4E, and eIF4E overexpression enhances cell growth and transforms cells by increasing the translation of a subset of key growth-promoting proteins, including cyclin D1, c-Myc, and vascular endothelial growth factor $(36,37)$. Therefore, mTOR-dependent regulation of both 4EBP1 and S6K might be one mechanism whereby mTOR positively regulates tumor progression, possibly affecting biological behavior and outcome. Further study with larger samples will be needed to elucidate the role of the activation of Akt and mTOR in cervical cancer.

In conclusion, our present study showed that cervical cancer expressed Akt and mTOR activation and the activation of mTOR may have a potential role in predicting the response to chemotherapy and prognosis of advanced cervical cancer treated with cisplatin-based neoadjuvant chemotherapy. Therefore, mTOR might be a potentially new target for therapeutic intervention in cervical cancer patients.

\section{Acknowledgements}

The auhors would like to thank Mr. T. Aoyagi for his excellent technical assistance. This work was supported by Grants-in-Aid for Scientific Research (C) 15591730 from the Ministry of Education, Culture, Sports, Science and Technology, Japan.

\section{References}

1. Ferlay J, Bray F, Pisani P and Parkin DM: Globocan 2002: Cancer incidence, mortality, and prevalence worldwide International Agency for Research on Cancer Cancer Base 5, Version 2.0. Lyon: IARC 2004.

2. Pisani P, Parkin DM, Bray F and Ferlay J: Estimates of the worldwide mortality from 25 cancers in 1990. Int J Cancer 83: 18-29, 1999.

3. Green JA, Kirwan JM, Tierney JF, Symonds P, Fresco L, Collingwood $\mathrm{M}$ and Williams CJ: Survival and recurrence after concomitant chemotherapy and radiotherapy for cancer of the uterine cervix: a systematic review and analysis. Lancet 358 : 781-786, 2001.

4. Benedet JL, Odicino F, Maisonneuve P, et al: Carcinoma of the cervix uteri. J Epidemiol Biostat 6: 7-43, 2001. 
5. Coffer PJ, Jin J and Woodgett JR: Protein kinase B (cAkt): a multifunctional mediator of phosphatidylinositol-3 kinase activation. Biochem J 335: 1-13, 1998.

6. Vivanco I and Sawyers CL: The phosphatidylinositol 3-kinaseAkt pathway in human cancer. Nat Rev Cancer 2: 489-501, 2002.

7. Hidalgo $\mathrm{M}$ and Rowinsky EK: The rapamycin-sensitive signal transduction pathway as a target for cancer therapy. Oncogene 19: 6680-6686, 2000.

8. Dennis PB, Jaeschke A, Saitoh M, Fowler B, Kozma SC and Thomas G: Mammalian TOR: a homeostatic ATP sensor. Science 294: 1102-1105, 2001.

9. Wlodarski P, Kasprzycka M, Liu X, Marzec M, Robertson ES, Slupianek A and Wasik MA: Activation of mammalian target of rapamycin in transformed lymphocytes is nutrients dependent but independent of akt, mitogen-activated protein kinase/extracellular signal-regulated kinase kinase, insulin growth factor-I, and serum. Cancer Res 65: 7800-7808, 2005.

10. Creasman WT: New gynecologic cancer staging. Gynecol Oncol 58: 157-158, 1995.

11. Therasse P, Arbuck SG, Eisenhauer EA, et al: New guidelines to evaluate the response to treatment in solid tumors. J Natl Cancer Inst 92: 205-216, 2000.

12. Freitas S, Moore DH, Michael H and Kelley MR: Studies of apurinic/apyrimidinic endonuclease/ref-1 expression in epithelial ovarian cancer: correlations with tumor progression and platinum resistance. Clin Cancer Res 9: 4689-4694, 2003.

13. Kreisberg JI, Malik SN, Prihoda TJ, Bedolla RG, Troyer DA, Kreisberg S and Gosh PM: Phosphorylation of Akt (Ser 473) is an excellent predictor of poor clinical outcome in prostate cancer. Cancer Res 64: 5232-5236, 2004

14. Perez-Tenorio G and Stal O: Southeast Sweden Breast Cancer Group: Activation of AKT/PKB in breast cancer predicts a worse outcome among endocrine treated patients. Br J Cancer 86: 540-545, 2002.

15. Maehama T and Dixon JE: The tumor suppressor PTEN/ MMAC1 dephosphorylates the lipid second messenger, phosphatidylinositol 3,4,5-triphosphate. J Biol Chem 273: 13375-13378, 1998.

16. Su TH, Chang JG, Perng LI, Chang CP, Wei HJ, Wang NM, and Tsai $\mathrm{CH}$ : Mutation analysis of the putative tumor suppressor gene PTEN/MMAC1 in cervical cancer. Gynecol Oncol 76: 193-199, 2000.

17. Cheung TH, Lo KW, Yim SF, et al: Epigenetic and genetic alteration of PTEN in cervical neoplasm. Gynecol Oncol 93: 621-627, 2004

18. Ma YY, Wei SJ, Lin YC, et al: PIK3CA as an oncogene in cervical cancer. Oncogene 23: 2739-2744, 2000.

19. Nicholson KM and Anderson NG: The protein kinase B/Akt signaling pathway in human malignancy. Cell Signal 14: 381-395, 2002.

20. Lee SH, Kim HS, Park WS, et al: Non-small cell lung cancers frequently express phosphorylated Akt; an immunohistochemical study. APMIS 110: 587-592, 2002.

21. David O: Akt and PTEN: new diagnostic markers of non-small cell lung cancer? J Cell Mol Med 5: 430-433, 2001.
22. Zhou X, Tan M, Stone Hawthorne V, et al: Activation of the Akt/mammalian target of rapamycin/4E-BP1 pathway by ErbB2 overexpression predicts tumor progression in breast cancers. Clin Cancer Res 10: 6779-6788, 2004.

23. Malik SN, Brattain M, Ghosh PM, Troyer DA, Prihoda T, Bedolla R and Kreisberg JI: Immunohistochemical demonstration of phospho-Akt in high Gleason grade prostate cancer. Clin Cancer Res 8: 1168-1171, 2002

24. Kurose K, Zhou XP, Araki T, Cannistra SA, Maher ER and Eng C: Frequent loss of PTEN expression is linked to elevated phosphorylated Akt levels, but not associated with p27 and cyclin D1 expression, in primary epithelial ovarian carcinomas. Am J Pathol 158: 2097-2106, 2001.

25. Lawlor MA and Alessi DR: PKB/Akt: a key mediator of cell proliferation, survival and insulin responses? J Cell Sci 114: 2903-2910, 2001.

26. Testa JR and Bellacosa A: AKT plays a central role in tumorigenesis. Proc Natl Acad Sci USA 98: 10983-10985, 2001.

27. Scheid MP and Woodgett JR: PKB/AKT: functional insights from genetic models. Nat Rev Mol Cell Biol 2: 760-768, 2001.

28. Mondesire WH, Jian W, Zhang H, Ensor J, Hung MC, Mills GB and Meric-Bernstam F: Targeting mTOR synergistically enhances chemotherapy-induced cytotoxicity in breast cancer cells. Clin Cancer Res 10: 7031-7042, 2004.

29. Yau CY, Wheeler JJ, Sutton KL and Hedley DW: Inhibition of integrin-linked kinase by a selective small molecule inhibitor, QLT0254, inhibit PI3K/PKB/mTOR, STAT3 and FKHR pathways and tumor growth, and enhances gemcitabine-induced apoptosis in human orthotopic primary pancreatic cancer xenograft. Cancer Res 65: 1497-1504, 2005.

30. Beuvink I, Boulay A, Fumagalli S, et al: The mTOR inhibitor RAD001 sensitizes tumor cells to DNA-damaged induced apoptosis through inhibition of p21 translation. Cell 120: 747-759, 2005.

31. Yamamoto S, Tomita Y, Hoshida Y, et al: Prognostic significant of activated Akt expression in pancreatic ductal adenocarcinoma. Clin Cancer Res 10: 2846-2850, 2004.

32. Dai DL, Martinka M and Li G: Prognostic significance of activated Akt expression in melanoma: A clinicopathologic study of 292 cases. J Clin Oncol 23: 1473-1482, 2005.

33. Vasko V, Saji M, Hardy E, et al: Akt activation and localisation correlate with tumour invasion and oncogene expression in thyroid cancer. J Med Genet 41: 161-170, 2004.

34. Avruch J, Belham C, Weng Q, Hara K and Yonezawa K: The p70S6 kinase integrates nutrient and growth signals to control translational capacity. Prog Mol Subcell Biol 26: 115-154, 2001.

35. Inoki K, Corradetti MN and Guan KL: Dysregulation of the TSC-mTOR pathway in human disease. Nat Genet 37: 19-24, 2005.

36. Gingras AC, Raught B and Sonenberg N: eIF4E initiation factors: effectors of mRNA recruitment to ribosomes and regulators of translation. Annu Rev Biochem 68: 913-963, 1999.

37. Mamane Y, Petroulakis E, Rong L, Yoshida K, Ler LW and Sonenberg N: eIF4E-from translation to transformation. Oncogene 23: 3172-3179, 2004. 